\title{
ANÁLISE DAS PRÁTICAS DE RESPONSABILIDADE SOCIAL NAS EMPRESAS DE DEFENSIVOS AGRÍCOLAS, NO MUNICÍPIO DE TANGARÁ DA SERRA - MT
}

\author{
Fátima Antonia de Oliveira Quinot ${ }^{1}$ \\ Luciênio Rosa e Silva Junior ${ }^{2}$
}

\begin{abstract}
RESUMO
O objetivo geral da pesquisa foi identificar quais ações de responsabilidade social estão sendo praticadas nas empresas de defensivos agrícolas de Tangará da Serra - MT. A metodologia utilizada foi a pesquisa descritiva, pois teve como finalidade observar, registrar e analisar os fenômenos sem, no entanto, entrar no mérito de seu conteúdo. Quanto aos meios, a pesquisa foi bibliográfica, fundamentada em livros e meios eletrônicos; e ainda realizou-se a investigação empírica, onde o fenômeno ocorre, com a coleta dos dados por meio de questionário, que determina-se pesquisa de campo. A presente pesquisa foi de natureza qualiquantitativa, considerando que apresenta os resultados quantitativos da coleta de dados, realizada no período de 21 a 23 de março de 2011, onde através dos resultados obtidos podese entender que todas as empresas de defensivos agrícolas praticam, de alguma forma, ações de responsabilidade social. O objetivo geral foi respondido através da figura 7 , onde verificou-se que os atos sociais mais praticados pelas empresas são as parcerias com outras entidades e participações com doações voluntárias.
\end{abstract}

Palavras-Chave: Responsabilidade, conhecimento, respeito a sociedade, integração.

\section{INTRODUÇÃO}

Há anos vem amadurecendo no Brasil o conceito de Responsabilidade Social nas empresas. A partir da década de 1990, desenvolver a cultura da responsabilidade social tornou-se quase um imperativo de gestão para as empresas que pretendem manterem-se competitivas no mercado. Muitas, porém, não encontram o caminho para um legítimo programa de responsabilidade social. Abrem-se assim os flancos para as críticas (MENDONÇA, 2004).

Com a exigência dos consumidores, o movimento da responsabilidade social tornou-se uma ferramenta útil para as empresas, já que esta prática poderá melhorar o desempenho de seus colaboradores, incentivando-os a produzir serviços e produtos com qualidade, e conseqüentemente gerando vantagem competitiva.

A responsabilidade social pressupõe o reconhecimento da comunidade e da sociedade como partes interessadas da organização, com necessidades que precisam ser atendidas (TINOCO, 2006). Pois faz a interação entre empresas e sociedades, satisfazendo os interesses

\footnotetext{
${ }^{1}$ Contadora formada pela UNEMAT - Campus de Tangará da Serra, fatimaquinot@ @otmail.com

${ }^{2}$ Mestre em Ciências Ambientais (UNEMAT), Professor do Departamento de Ciências da UNEMAT - Campus de Tangará da Serra, lucieniojunior@unemat.br
} 
múltiplos. A responsabilidade social é um conjunto de conceitos e ações que contribui para fazer um mundo melhor com a participação de todos, incluindo tomada de decisões para que este fim seja alcançado (AMADO, 2010). E para entender melhor a prática de responsabilidade social, foi levantada a seguinte questão de pesquisa: as empresas de defensivos agrícolas de Tangará da Serra - MT praticam responsabilidade social? Neste sentido esta pesquisa tem como objetivo identificar quais ações de responsabilidade social estão sendo praticadas nas empresas de defensivos agrícolas de Tangará da Serra - MT.

\section{REFERENCIAL TÉORICO}

\subsection{RESPONSABILIDADE SOCIAL}

A Responsabilidade Social das Empresas (RSE) é um movimento que teve seu início nos anos 60. Proliferou nos Estados Unidos da América (EUA) fundamentando - se na busca por maior consciência da sociedade em relações à responsabilidade das empresas, na preservação do meio ambiente e dos direitos dos consumidores (REIS; MEDEIROS, 2009).

[...] o conceito de responsabilidade social está se ampliando, passando da filantropia, que é a relação socialmente compromissada da empresa, para abranger todas as relações da empresa: com seus funcionários, clientes, fornecedores, acionistas, concorrentes, meio ambiente e organizações públicas e estatais (NETO; FROES, 1999, p. 79).

Esta prática é uma forma das empresas conduzirem seus negócios de tal maneira que as tornem parceiras e corresponsáveis pelo desenvolvimento social. A empresa socialmente responsável é aquela que possui a capacidade de ouvir os interesses das diferentes partes envolvidas no negócio (stakeholders): acionistas, funcionários, fornecedores, consumidores, comunidade, governo e meio ambiente, de forma a conseguir incorporá-los no planejamento de suas atividades, buscando atender às demandas de todos (ALESSIO, 2003).

A responsabilidade social possui duas vertentes: interna e externa. Responsabilidade social interna é voltada para o público interno com ênfase nas áreas da educação, salário e benefícios, assistência médica, social e odontológica. O objetivo principal é obter maior retorno de produtividade para os acionistas e melhores incentivos aos colaboradores. Responsabilidade social externa tem como foco a comunidade, através de ações sociais principalmente para as áreas de educação, saúde, assistência social e ecologia e envolve retorno social, de imagem, publicitária para os acionistas (NETO; FROES, 1999). 
O quadro 1 apresentam alguns exemplo de responsabilidade social interna e externa.

\begin{tabular}{|c|c|c|}
\hline & $\begin{array}{c}\text { RESPONSABILIDADE SOCIAL } \\
\text { INTERNA }\end{array}$ & $\begin{array}{c}\text { RESPONSABLIDADE SOCIAL } \\
\text { EXTERNA }\end{array}$ \\
\hline FOCO & $\begin{array}{l}\text { Público interno (Empregados e seus } \\
\text { dependentes) }\end{array}$ & Comunidade \\
\hline $\begin{array}{l}\text { ÁREAS DE } \\
\text { ATUAÇÃO }\end{array}$ & $\begin{array}{l}\text { - Educação } \\
\text { - Salários e benefícios } \\
\text { social e odontológica }\end{array}$ & $\begin{array}{l}\text { - Educação } \\
\text { - Saúde } \\
\text { - Assistência social } \\
\text { - Ecologia }\end{array}$ \\
\hline INSTRUMENTOS & $\begin{array}{l}\text { - Programas de recursos humanos } \\
(\mathrm{PH}) \\
\text { - Planos de previdência complementar }\end{array}$ & $\begin{array}{l}\text { - Doações } \\
\text { - Programas de voluntariado } \\
\text { - Parcerias } \\
\text { - Programas e projetos sociais }\end{array}$ \\
\hline $\begin{array}{l}\text { TIPOS DE } \\
\text { RETORNO }\end{array}$ & $\begin{array}{l}\text { - Retorno de produtividade } \\
\text { - Retorno para acionistas }\end{array}$ & $\begin{array}{l}\text { - Retorno social propriamente dito } \\
\text { - Retorno de imagem } \\
\text { - Retorno publicitário } \\
\text { - Retorno para os acionistas }\end{array}$ \\
\hline
\end{tabular}

Quadro 1: exemplos de responsabilidade interna e externas.

Fonte adaptada de Neto e Froes, 1999.

O exercício da responsabilidade social incorpora na cultura da organização a busca do bem estar da sociedade, associado ao seu próprio crescimento. Com a prática e a evidenciação da responsabilidade social, as empresas adquirem retorno institucional e a valorização da sua imagem, beneficiando tanto a ela como a sociedade (MARIN, 2008). A organização que exerce o papel de empresa-cidadã se torna reconhecida pela excelente atuação na área social e ganha confiança, respeito, e admiração dos consumidores (NETO; FROES, 1999).

A responsabilidade social das empresas, em seu sentido, mais amplo, é a consciência ética, o agir corretamente, o compromisso de "ser responsável" ao não tomar decisões, cujas conseqüências possam causar danos quaisquer aos interesses sociais, sejam internos ou externos, ou seja, é ter responsabilidade perante os problemas sociais que assolam o mundo tomando atitudes concretas para enfrentá-los por uma questão de valor moral e ético de compromisso humano e social (REIS; MEDEIROS, 2009).

Fernandes (2000) descreve a responsabilidade social como um conjunto de obrigações inerentes para o crescimento de um estado ou condição com forças ainda não reconhecidas 
pelo ordenamento jurídico positivo ou desconhecidas parcialmente, e cuja força que vincula e sua prévia tipificação procedem da íntima convicção social de que não segui-la constitui uma transgressão da norma e da cultura.

\subsection{BALANÇO SOCIAL}

O Balanço Social foi instituído na França, em 1977, com uma visão restrita a recursos humanos. Com o tempo, ganhou uma abordagem mais ampla, contemplando, além dos dados relativos a esses recursos, a questão ambiental, a cidadania e o valor agregado à economia do país (RIBEIRO, 2006). Esse relatório favorece a todos os grupos que estão diretamente ligados e que interagem com a empresa. O processo de realização de projetos voltados à questão social estimula a participação dos funcionários na escolha das ações e projetos sociais, gerando um grau mais elevado de comunicação interna e integração nas relações entre dirigentes e o corpo funcional (SILVA; FREIRE, 2001).

O Balanço Social é um demonstrativo que a empresa socialmente responsável publica anualmente, que reúne um conjunto de informações sobre os projetos, benefícios e ações sociais dirigidas aos empregados, investidores, analistas de mercado, acionistas e à comunidade. É um instrumento estratégico para avaliar e multiplicar o exercício da responsabilidade social corporativa (NETO; FROES, 1999). É um relatório que a empresa elabora e publica para demonstrar seus investimentos, despesas com seus colaboradores e com a sociedade como um todo, inclusive com a abrangência de assuntos ambientais.

\footnotetext{
O balanço social é a expressão mais evidente e equivocada da cidadania empresarial. Certamente estamos caminhando para um tempo de "muito milhares de balanços sociais" no Brasil, com seu elenco de realizações positivas. Um tempo que já chegou para muitas empresas e ainda vai chegar para muitas outras (NETO; FROES, 1999, p. 125).
}

Pode-se entender que todas as empresas que se considerem atualizadas com informações sociais deverão estar em constante busca por mudanças, para que possam enfrentar o mercado atual, já que a cada dia surgem novas idéias de responsabilidade social e que forçam as empresas a publicar seu balanço social. Elaborar o Balanço Social é um estímulo à reflexão sobre as ações das empresas no campo social, pois ele estimula o controle social sobre o uso dos incentivos fiscais e outros mecanismos de compreensão de gastos com colaboradores, além de ajuda na identificação de políticas de recursos humanos e servir como 
parâmetro de ações dos diferentes setores da empresa, no campo das políticas sociais (SILVA; FREIRE, 2001).

Aprovado em 23 de outubro de 1998, o projeto $n^{\circ}$ 39/97, que cria o dia e o "selo Empresa Cidadã do Município de São Paulo”, transformou-se na Resolução nº 05/98, que estabelece, em nível municipal, 25 de outubro como o "Dia da Empresa Cidadã", concedendo um selo/certificado para toda a empresa que apresentar qualidade em seu Balanço Social anual. O Balanço Social é o diferencial da empresa perante seus clientes, investidores, e sociedade em geral (SILVA; FREIRE, 2001).

O balanço social como instrumento de divulgação da responsbilidade social das entidades, correlacionando a empresa de modo objetivo para com a sociedade, necessita com relação às informações que divulga, observar determinados pressupostos, os quais podem acarretar limitações no que tange a essa ideia de demonstração, como a privacidade, pois a demonstração do balanço social não deve atentar contra os direitos em termos de privacidade dos indivíduos ou das instituições, devem ter o consentimento das partes interressadas, a não ser em caso de exigência legal, impondo-se, de modo geral, como necessidade ética (REIS; MEDEIROS, 2009).

Para os consumidores, o balanço social dá uma idéia de qual é a postura dos dirigentes e a qualidade do produto ou serviço oferecido, demonstrando o caminho que a empresa escolheu para construir sua marca. E ao Estado, ajuda na identificação e na formulação de políticas públicas (SILVA; FREIRE, 2001).

Diante da deficiência do Estado em suprir nossas severas demandas sociais, empresas atuam de forma proativa e incorporam um discurso social mais justo. Na face de uma crescente cobrança por transparência, não basta hoje atuar de forma responsável, mas é preciso mostrar resultados. Por isso, empresas demonstram transparência em seus relatórios sociais das mais diversas formas e modelos (RESPONSABILIDADE SOCIAL, 2011).

O quadro 2 apresenta o modelo de Balanço Social, de acordo com o IBASE (Instituto Brasileiro de Análises Sociais e Econômicas). 


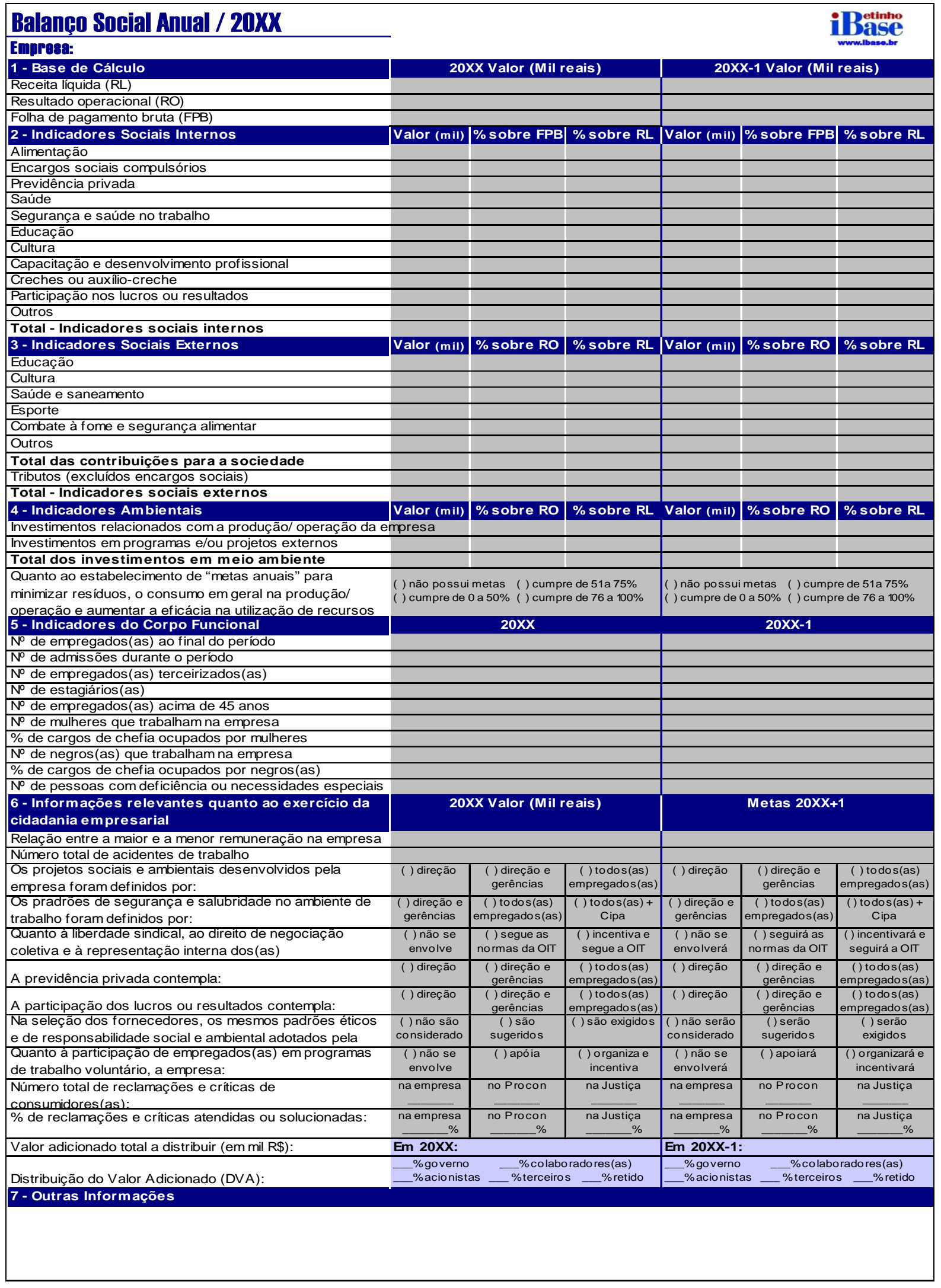

Quadro 2: Modelo Balaço Social Fonte: Instituto Brasileiro de Análises Sociais e econômicas (IBASE, 2011). 
O balanço social serve para a empresa entender onde e de que modo ela aplicou seus recursos com ações sociais, sejam internas ou externas, e que poderá gerar incentivo fiscal.

\subsection{PROJETOS E ACÕES DE RESPONSABILIDADE SOCIAIS}

O que mais cresce em nosso País é a modalidade de ação de investimentos em projetos e programas de responsabilidade social. Algumas empresas nacionais e corporações multinacionais estão criando institutos sociais para administrar suas próprias ações sociais, outras empresas financiam diretamente programas projetos da comunidade, e algumas desenvolvem seus próprios projetos e programas sociais. Cresce o volume investido em patrocínio de projetos de ações direcionadas a sociedade, principalmente os que contam com o apoio do governo e de entidades (NETO; FROES, 1999).

As parcerias constituem uma área em expansão que é considerada o mais novo modelo de investimento no terceiro setor que congrega recursos do governo, empresas privadas, comunidade, ONG`s e demais entidades. Os projetos são, portanto, desdobramentos dos programas, e estes, de um único plano. Ou melhor, um plano contém diversos programas, e um programa, diversos projetos (NETO; FROES, 1999).

No Brasil existem diversos projetos e ações de responsabilidade social, entre eles podem se destacar, por exemplo, Banco do Brasil que possui o Programa de Trabalho e Cidadania, realizado pela fundação Banco do Brasil e Ministério do Trabalho, promove cursos de capacitação profissional para trabalhadores com mais de 14 anos de idade, com recursos provenientes do Fundo de amparo ao trabalhador (FAT). Em 1997, cursos nas áreas de educação, saúde, agricultura, informática, serviços, indústria e turismo beneficiaram cerca de 14 mil trabalhadores, utilizando recursos da ordem de R 7 milhões (TINOCO, 2006).

Outro banco envolvido com a questão da educação é o Itaú, que também enxerga no tema uma das principais vias de garantia do desenvolvimento sustentável. A Fundação Itaú Social destina-se à implantação e disseminação de metodologias voltadas à políticas públicas na área educacional e à avaliação de projetos sociais, colaborando com a formação de cidadãos por meio de bolsa de estudos. O Itaú investiu $\mathrm{R}$ \$ 26 milhões em diversos programas sociais, voltados às áreas de ensino fundamental e saúde pública, e também contribuiu financeiramente com programas de alfabetização, além de estimular as famílias atingidas pela seca a manterem seus filhos na escola (TINOCO, 2006). 
A BASF, uma das principais fabricantes de defensivos agrícolas do país, possui uma ampla política de responsabilidade social. Neste contexto e com o objetivo de aumentar a conscientização das pessoas, desenvolveu o Projeto "Químico na Vida - Como Prevenir Acidentes Domésticos", uma ação educativa voltada para as escolas (crianças de $1^{\text {a a }} 4^{\mathrm{a}}$ série) e com o objetivo de esclarecer sobre os riscos e benefícios dos produtos químicos, orientandoas sobre como prevenir acidentes domésticos. Atualmente, existem mais 20 milhões de substâncias químicas artificiais catalogadas. Diariamente as pessoas entram em contato com mais de 150 mil delas, o que pode proporcionar benefícios e alguns riscos (AMARAL, 2006).

Os maiores inimigos dos produtos químicos são a desinformação, o descuido e o descaso das pessoas. As estatísticas mostram que grande parte dos acidentes com produtos químicos ocorrem dentro de ambientes domésticos, e as maiores vítimas são as crianças. A BASF realizou pesquisas e buscou ajuda de especialistas na área de toxicologia e pedagogia para desenvolver um filme em desenho animado com 12 minutos de duração, denominado "Produtos Químicos - Como prevenir acidentes domésticos". Além do filme educativo, a empresa desenvolveu outros materiais de apoio, como cartilha, manual de orientação para professores, ficha para cadastramento de professores, pais ou responsáveis e alunos (AMARAL, 2006).

Portanto, se vê a grande preocupação das empresas em melhorar o bem estar da sociedade, buscado meios e recursos para que os projetos de ações de responsabilidade social sejam alcançados da melhor forma possível.

\subsection{DEFENSIVOS AGRÍCOLAS}

Os defensivos agrícolas estão diretamente ligados à economia, pois todo o setor da agricultura e pecuária necessita desses insumos para um melhor desempenho produtivo. Se comparar as lavouras que usam os defensivos e as que não usam, a qualidade da produtividade das que usam é maior (BIOMANIA, 1999). A maneira de utilização de defensivos agrícolas e os conhecimentos básicos de aplicação são ferramentas úteis no controle de doenças, pragas e plantas daninhas. Seu uso na propriedade exige que o proprietário e os aplicadores tenham um conhecimento básico sobre o modo de ação, doses recomendadas, hora e época da aplicação, formulação do produto, classe toxicológica e cuidados durante e após a aplicação e manuseio do produto. Além de cuidados com o uso, existem as penalidades, como infrações e multas para o transportador e o expedidor, que não 
cumprirem as regulamentações de transporte, variando de 123,4 UFIRs a 617 UFIRs, sendo que o veículo irregular será apreendido e a carga transbordada, caso hajam acidentes de transporte que provoquem danos ambientais por não atenderem às normas vigentes, e ambos serão enquadrados na Lei de Crimes Ambientais (Art. 56 da Lei 9.605 de 13 de fevereiro de 1998), onde está previsto multa, reparação do meio ambiente atingido e até mesmo pena de reclusão de 2 a 4 anos aos infratores, de acordo com a ABRAPA - Associação Brasileira de Produtores de Algodão ( SILVA, 2011).

\footnotetext{
Os defensivos agrícolas fazem parte da agricultura, desde os primórdios, há cerca de 3.000 anos os gregos e romanos utilizavam esses produtos em suas lavouras e na criação de animais. Compostos orgânicos naturais obtidos das flores eram utilizados como inseticidas, logo na seqüência os chineses começaram a utilizar esse procedimento. Os povos no deserto utilizavam pó de piretro sobre os grãos, e feixes de flores nas portas de suas tendas como repelente de moscas e mosquitos (ALVES FILHO, 2002, p. 19).
}

O desenvolvimento da indústria de síntese química acarretou a difusão e a larga e progressiva utilização de biocidas sintetizados. Foi a partir de 1946 que os compostos começaram a fazer parte da agricultura brasileira. Entre 1954 a 1960, ouve um intenso processo junto ao Ministério da Agricultura, para que se tivesse liberação para lançar novos produtos. A partir de então, a variedade de insumos para a agricultura, desenvolvidos pela indústria química mundial colocados no mercado é enorme devido a evolução tecnológica, e a adequação do uso dos equipamentos em função das modernas teorias de defesas sanitárias vegetais, todas baseadas nos fatores básicos da tecnologia de aplicação (ALVES FILHO 2002).

Contudo Aves Filho 2002, destaca essas inovações tem o lado positivo e negativo, são eles:

\section{Pontos positivos:}

- controlam as doenças produzidas por vetores;

- aumentam a quantidade de produtos disponíveis, diminuindo seus custos;

- aumentam o lucro dos produtores;

- funcionam melhor e mais rápido no combate das pragas; e

- relativamente são produtos mais seguros, pois estão sendo continuamente alvos de estudos e desenvolvimento.

\section{Pontos negativos:}

- cria-se um círculo vicioso dos agrotóxicos; 
- a mobilidade dos agrotóxicos no meio ambiente;

- ameaças à vida silvestre;

- ameaças de curto prazo à saúde humana pelo uso e fabricação de agrotóxicos; e

- ameaça em longo prazo à saúde humana.

O crescente reconhecimento social dos riscos presentes no uso de agrotóxicos é o catalisador de iniciativas crescentes no sentido de buscarem adequações tecnológicas para a racionalização do uso de agrotóxicos, nesse sentido as empresas que fazem uso de agrotóxico estão cada vez mais sendo obrigados a se preocupar com a reciclagem e armazenamento adequado da embalagem dos defensivos necessário para um melhor resultado na produtividade (ALVES FILHO, 2002).

Os principais órgãos responsáveis pelo registro de defensivos agrícolas, avaliação e concessão do registro de defensivos são de responsabilidade de três órgãos federais: Ministério da Agricultura, Pecuária e Abastecimento (MAPA), Instituto Brasileiro de Meio Ambiente (IBAMA), vinculado ao Ministério do Meio Ambiente, e Agência Nacional de Vigilância Sanitária (ANVISA), do Ministério da Saúde. Antes de serem levados para a análise desses três órgãos, há o trabalho de centenas de especialistas em regulamentação e registro, pertencentes aos quadros das indústrias, que analisam a segurança e eficácia dos defensivos agrícolas (ANDEF), dentro de padrões internacionalmente aceitos (ANDEF, 2011).

\section{METODOLOGIA}

Esta pesquisa é de natureza descritiva com abordagem quantitativa. A pesquisa foi realizadas nas empresas de defensivos agrícolas no município de Tangará da Serra - MT, através da coleta de dados, realizada no período de 21 a 23 março de 2011, onde foram visitadas um total de 16 empresas existentes e foi aplicado questionário contendo 11 perguntas (fechadas) que foram respondidas pelos proprietários e funcionários colaboradores das empresa, todas localizadas no município de Tangará da Serra - MT, segundo dados da Prefeitura Municipal de Tangará da Serra - MT, relatados em fevereiro de 2011.

\section{RESULTADOS E DISCUSSÕES}


A questão 1 buscou identificar o tempo de existência da empresa, identificou-se que $37,50 \%$ estão na atividade entre 11 e 20 anos, e $25 \%$ entre 6 e 10 anos, também com o mesmo resultado há mais de 20 anos, de 1 a 5 anos ficou com 12,50\%, menos de 1 ano não pontuaram (Figura 01).

\section{Há quantos anos a empresa está instalada em Tangará da Serra-}

MT?

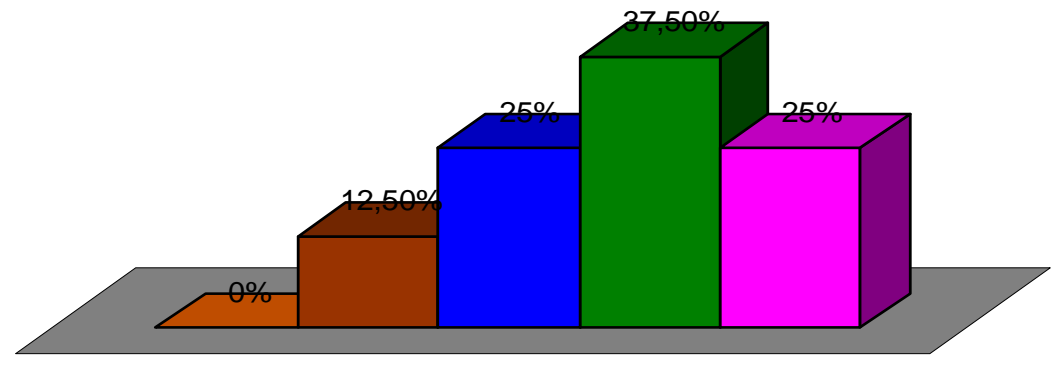

$\square$ Menos de 1 ano $\square$ De 1 a 5 anos

- De 6 a 10 anos

$\square$ De 11 a 20 anos

$\square$ Mais de 20 anos

Figura 1 - Tempo de existência das empresas

Fonte: Elaborada pela autora.

Na questão 2, com o questionamento de qual era a participação do entrevistado na empresa, as respostas obtidas foram que $68,75 \%$ dos pesquisados são funcionários colaboradores, sendo que, no entanto, a pesquisa focou em entrevistar os gerentes ou os proprietários delas, como é indicado através dos dados apresentados (Figura 2).

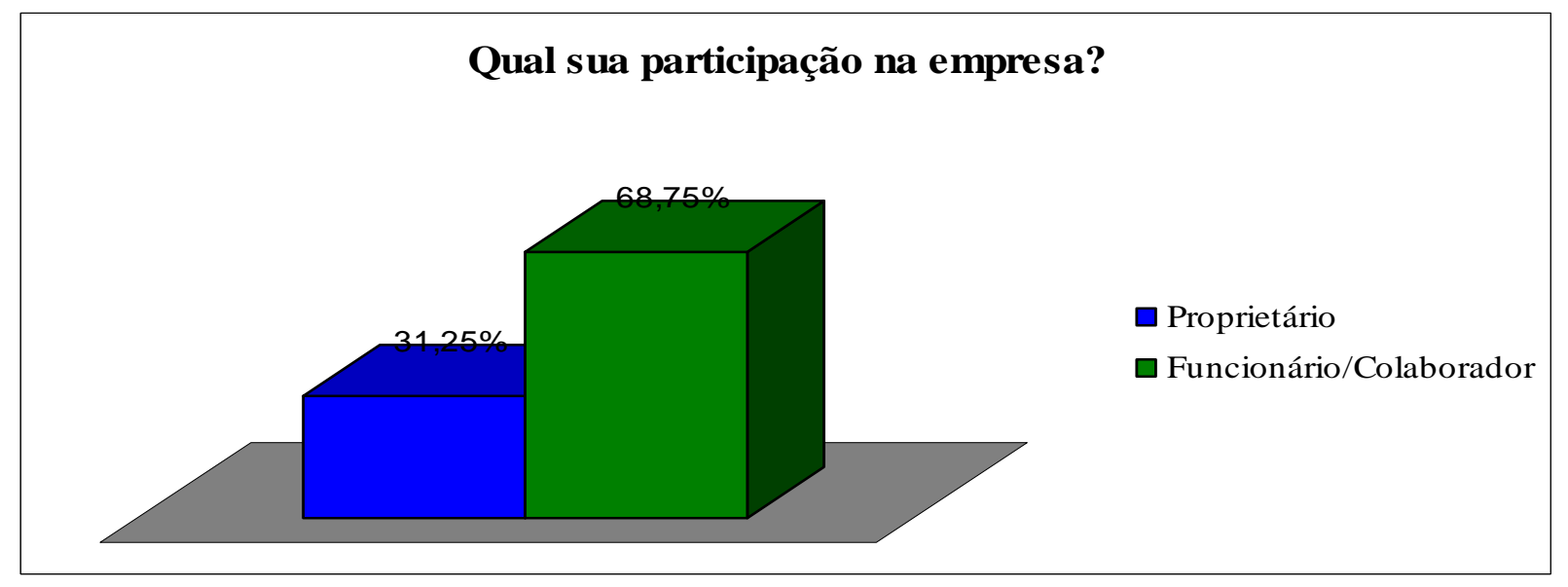

Figura 2 - Índice de participação na empresa.

Fonte: Elaborada pela autora.

A questão 3 tinha como objetivo identificar se os entrevistados tem algum conhecimento sobre projetos de responsabilidade social, $87,50 \%$ confirmaram ter 
conhecimento acerca do assunto, 6,25\% afirmaram não ter conhecimento e 6,25\% disseram que já ouviram falar a respeito, porém não sabem definir o conceito (Figura 3).

\section{Você tem conhecimento do que é um projeto de responsabilidade social?}

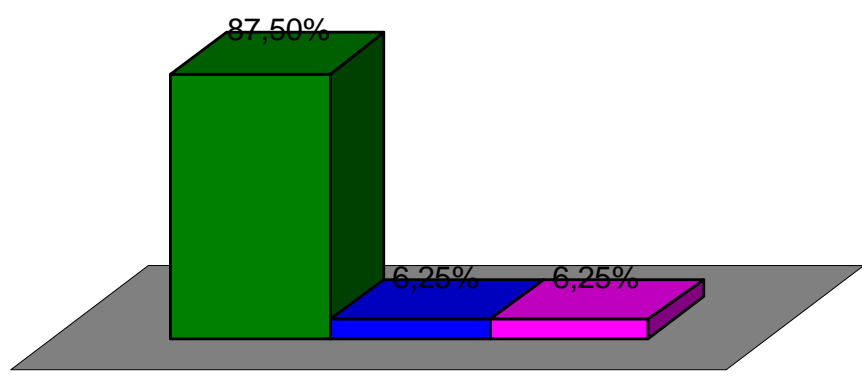

$\square \operatorname{Sim}$

$\square$ Não

$\square$ Já ouvi a respeito mas não sei definir o conceito

Figura 3 - Índice de conhecimento sobre responsabilidade social.

Fonte: Elaborada pela autora.

Quanto à questão 4, se considera importante que as empresas participem de projetos sociais, obteve-se um resultado relevante, pois todos responderam (100\%) que consideram importante que as empresas participem de projetos sociais (Figura 4).

\section{Para você é importante que as empresas participem de projetos} sociais?

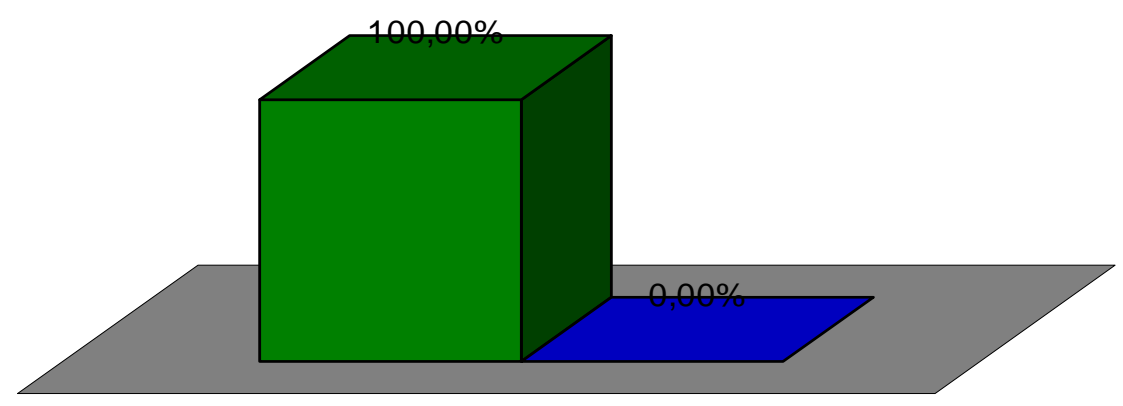

Figura 4 - Índice de importância de empresas que participam de projetos sociais. Fonte: Elaborada pela autora.

A questão 5, que analisou se as empresas participam de algum projeto social, apresentou índice considerável e o resultado foi relevante, pois $68,75 \%$ dos pesquisados afirmam que participam de algum projeto social. Assim, pode-se dizer que estas empresas, de algum modo, são socialmente responsáveis (Figura 5). 


\section{A empresa onde você atua participa de algum projeto social?}

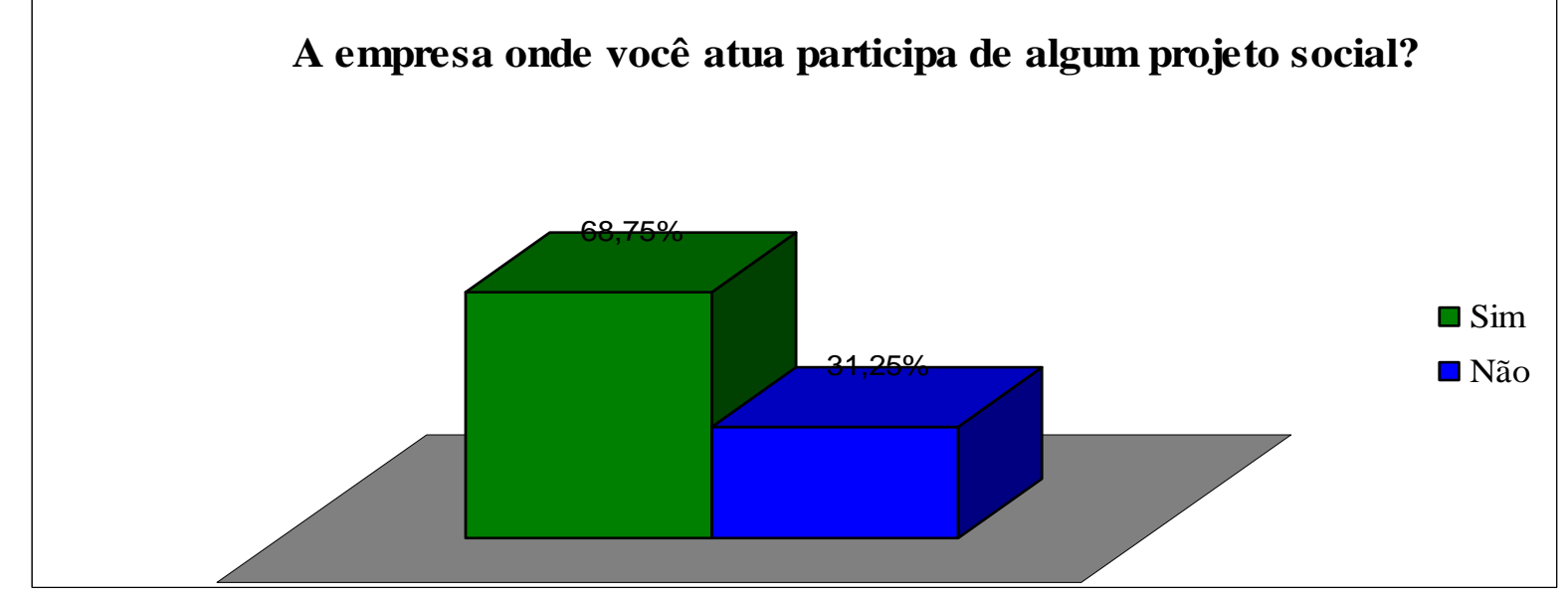

Figura 5 - Participação da empresa em projeto social.

Fonte: Elaborada pela autora.

Quando questionados há quanto tempo as empresas participavam de projetos sociais, $40 \%$ dos entrevistados responderam que há aproximadamente 5 anos, $30 \%$ responderam que entre 6 e 10 anos fazem parte de algum projeto, e 20\% afirmam que há mais de 10 anos participam de projetos sociais ( Figura 6).

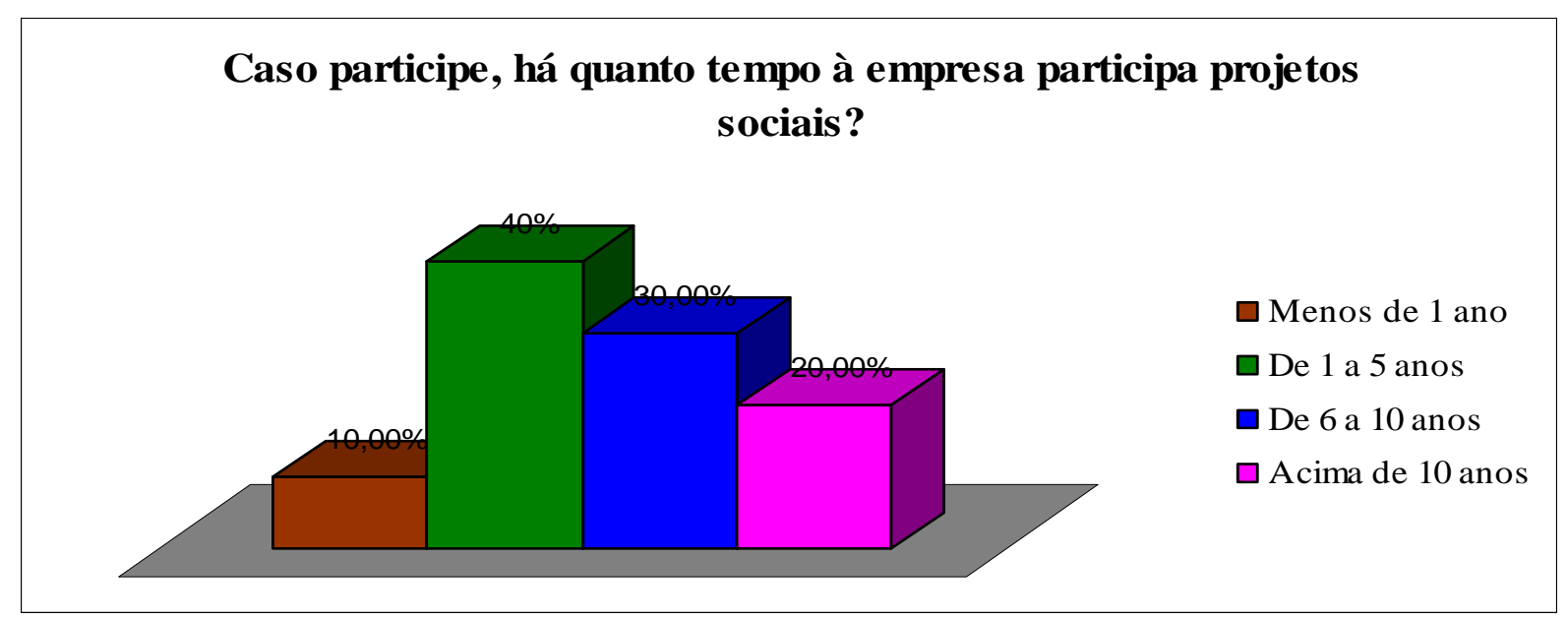

Figura 6 - Tempo de participação em projetos sociais.

Fonte: Elaborada pela autora.

A questão que abordou sobre quais os projetos que as empresas participam mostrou que $18,75 \%$ disseram que auxiliam seus funcionários com moradia, plano de saúde e auxílio alimentação, onde na mesma pergunta $31,25 \%$ optaram por responder mais que uma alternativa, o que esclarece que essas organizações não participam com um só tipo de projeto, e sim com vários, de acordo com o apresentado na figura 7. 


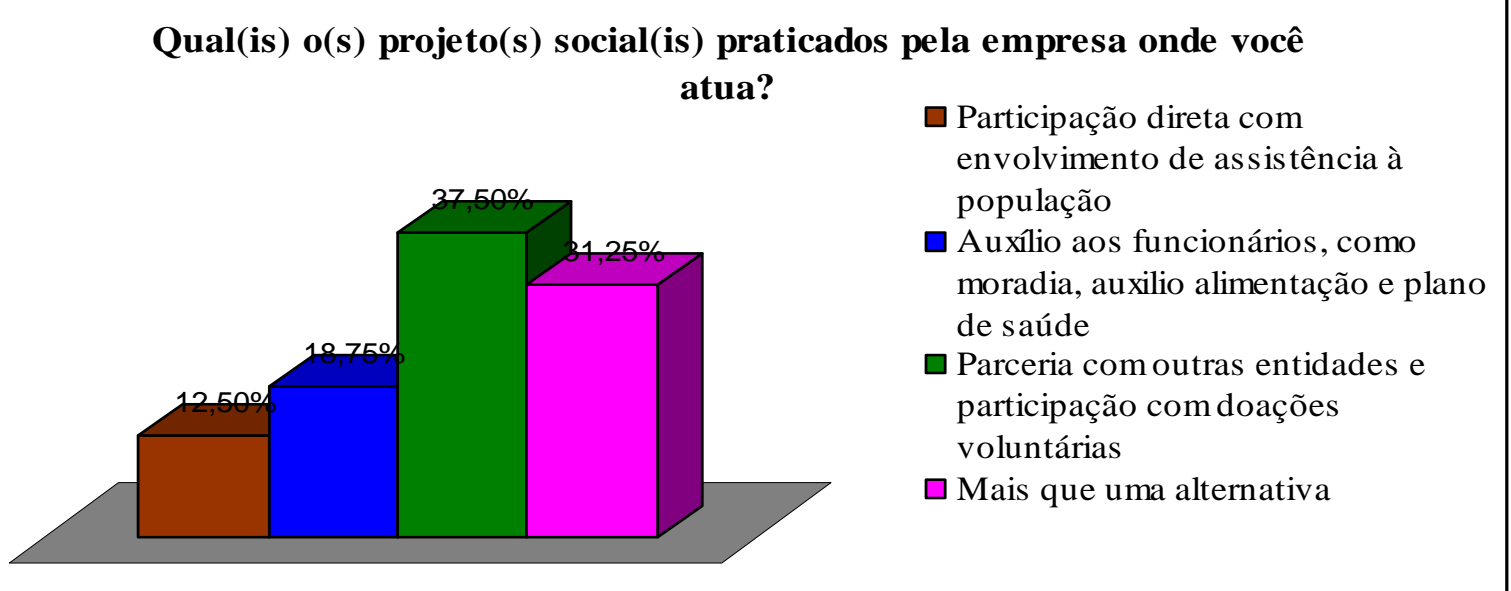

Figura 7 - Tipos de projetos sociais que as empresas participam.

Fonte: Elaborada pela autora.

Com os dados apresentados na figura 8, entende-se que as empresas consideram relevante participar de projetos sociais, já que isso, na visão da empresa, reflete como incentivo a seus colaboradores, gerando maior produtividade, como afirmaram $43,75 \%$ dos entrevistados. Outro dado importante está relacionado ao prestígio da empresa perante a sociedade, conforme $25 \%$ das respostas. Os demais $25 \%$ optaram por mais de uma alternativa (Figura 8).

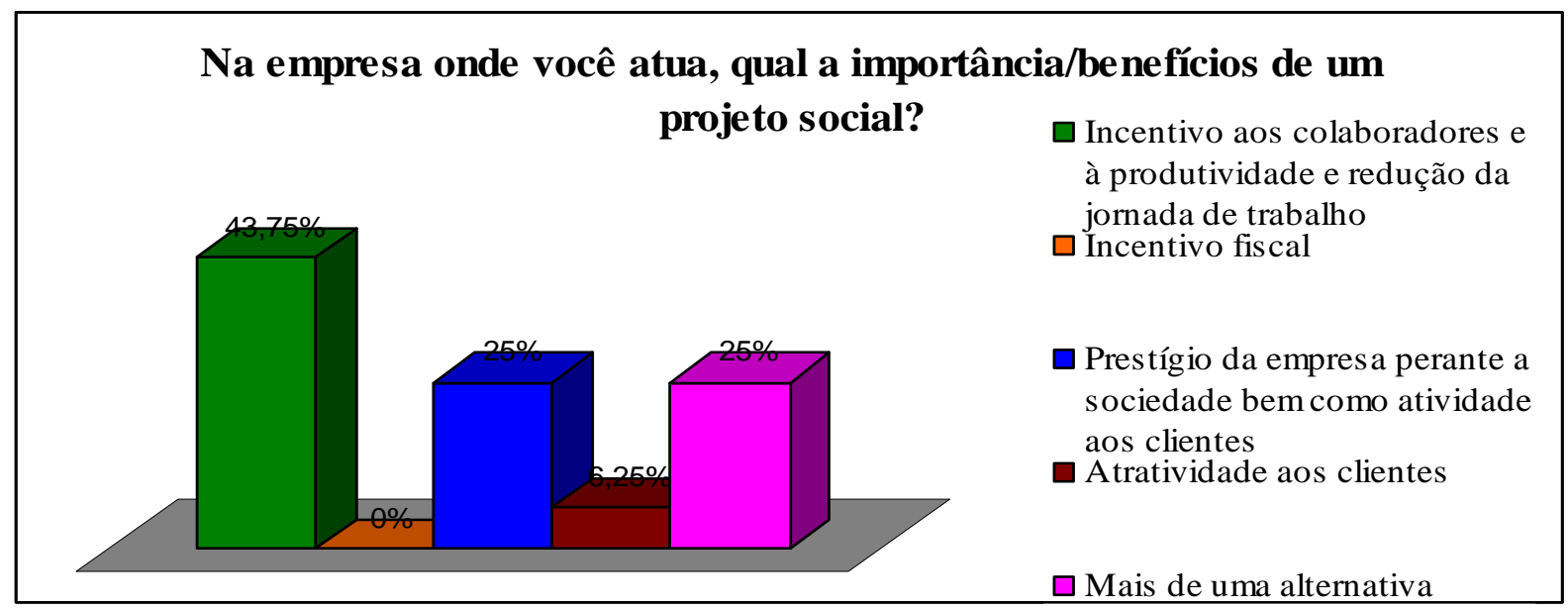

Figura 8 - Índice de importância em participar de projetos sociais.

Fonte: Elaborada pela autora.

Todas as empresas apresentaram-se bastante responsáveis, conforme o resultado obtido na figura 9 , uma vez que $87,50 \%$ deixaram evidente que os objetivos e metas da empresa são bem esclarecidas perante os colaboradores, onde todos participam de forma responsável e de certo modo asseguram à sociedade os seus reflexos, intermediando-os com a organização. 


\section{Todos na empresa estão cientes dos objetivos, e metas, programas e responsabilidade social?}

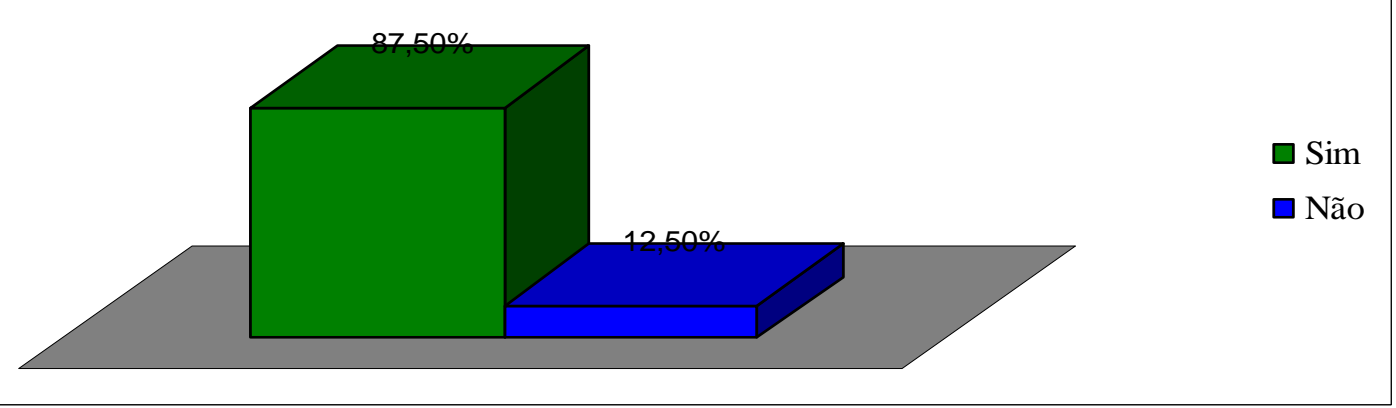

Figura 9 - Índice de transparência dos objetivos e metas dos programas de responsabilidade social.

Fonte: Elaborada pela autora.

Os números evidenciaram que as empresas estão procurando inovar, bem como selecionam colaboradores que estejam empenhados em vender bens e serviços que satisfaçam seus clientes, atendendo assim todas as suas necessidades e até mesmo respondendo possíveis reivindicações que surjam, pois $68,75 \%$ dos questionados afirmaram que estão preparados para responder a sociedade diante de reivindicações posteriores.

\section{Há na empresa procedimentos estabelicidos para responder às reivindicações da comunidade?}

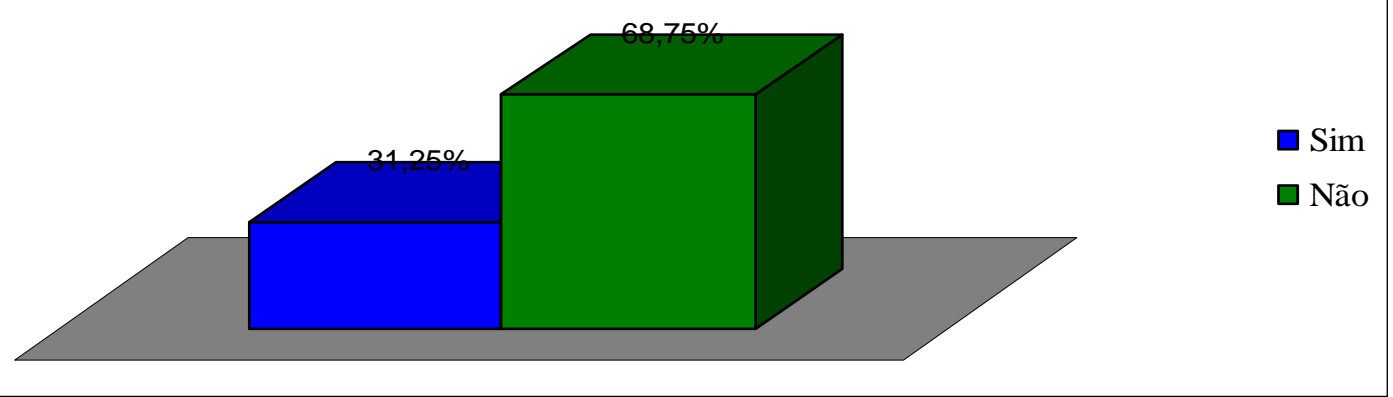

Figura 10- Índice dos procedimentos estabelecidos para responder às reivindicações. Fonte: Elaborada pela autora.

Quando questionados se a empresa elabora e publica algum relatório, contábil ou social, obteve-se um resultado que leva a compreender que as empresas temem em falar em algo que supostamente pode comprometer a empresa, uma vez que um relatório contábil apresenta suas informações gerais.

A figura 11 evidencia que $75 \%$ responderam que não elaboram e nem publicam 
relatórios contábeis, o que assim leva a entender de que modo essas empresas contabilizam as despesas com doações, já $25 \%$ das empresas responderam que elaboram os relatórios, porém não os publicam, justificando que não é importante publicar os resultados da organização.

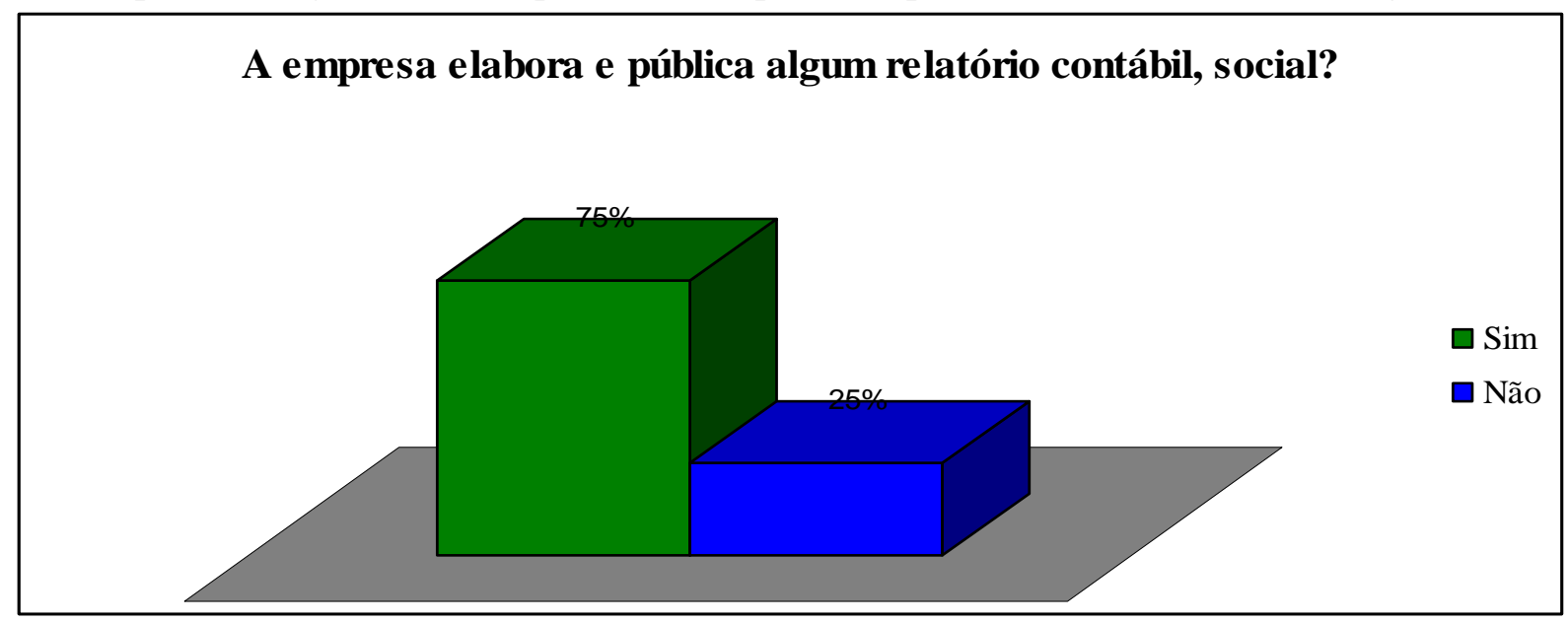

Figura-11 Indice de relatório contabil, social.

Fonte: Elaborada pela autora.

\section{CONSIDERAÇÕES FINAIS}

Este artigo obteve como problema de pesquisa: Analisar se as empresas de defensivos agrícolas de Tangará da Serra - MT praticam responsabilidade social. Teve como objetivo identificar quais ações de responsabilidade social estão sendo praticadas nas empresas de defensivos agrícolas de Tangará da Serra - MT. As respostas ao problema surgem ao avalizar todos os gráficos, os quais apresentam números relevantes em todas as questões apresentadas e que levam a afirmação que as empresas de defensivos agrícolas do município de Tangará da Serra - MT praticam ações de responsabilidade social. Quanto ao objetivo, foi alcançado através da figura 7, onde pôde-se verificar que os atos sociais praticados pelas empresas são: as parcerias com outras entidades e participações com doações voluntárias, participação direta com envolvimento de assistência à população, auxílio aos funcionários, como moradia, auxílio alimentação, plano de saúde etc.

$\mathrm{Na}$ análise das respostas adquiridas com o instrumento de pesquisa (questionário), todas as respostas obtidas vêm confirmar que a responsabilidade social é o ato de envolver-se com os problemas internos da organização, as quais estão sendo praticadas; os resultados foram coerentes com todos os questionamentos em estudo, e contribuíram com a sociedade apresentando as principais empresas de defesivos agrícola socialmente responsáveis, o que poderá influenciar outras empresas a praticar estas ações. 
Este artigo contribuiu para um melhor conhecimento sobre responsabilidade social, por meio da pesquisa, mostrando o grande envolvimento das empresas agrícolas com a sociedade e colaboradores, onde a participação destas empresas está cada vez maior, buscando sempre o bem estar entre todas as pessoas envolvidas. Os autores também mostram a relevância do estudo na área da contábil, onde apresentam conceitos sobre o assunto abordado.

Portanto por ser um tema que está em evidência no mercado, é importante a iniciação de futuros estudos ou até uma pesquisa em outras empresas de segmentos diferentes, mas utilizando de projetos socioambientais, para que se possa verificar essas práticas na cidade de Tangará da Serra - MT.

\section{REFERÊNCIAS BIBLIOGRÁFICAS}

ALESSIO, Rosemeri. Responsabilidade Social das Empresas no Brasil: Reprodução de Posturas ou Novos Rumos - 2003. Disponível em: <http://revistaseletronicas.pucrs.br/ojs/index.php/fass/article/viewFile/952/732> Acesso em: 13 de maio de 2011.

ALVES FILHO, José prado. Uso de agrotóxicos no Brasil - São Paulo: Annablume, Fapesp, 2002.

AMADO, Luciano. O que é Responsabilidade Social - 2010. Disponível em: <http://www.artigonal.com/authors/526369> Acesso em: 14 de maio de 2011.

AMARAL, Joelma. BASF leva projeto de prevenção de acidentes domésticos com produtos químicos para Juazeiro (BA) - 2006. Disponível em:

<http://www.basf.com.br/default.asp?id=3651> Acesso em: 29 de junho de 2011.

ANDEF. O que são defensivos agrícolas - 2011. Disponível em:

<http://www.andef.com.br/defensivos/index.asp?cod=4> Acesso em: 15 de maio de 2011.

BIOMANIA. Defensivos Agrícolas - 1999. Disponível em:

<http://www.biomania.com.br/bio/conteudo.asp?cod=1443> Acesso em: 10 de maio de 2011.

FERNANDES, Ângela. A Responsabilidade Social e a Contribuição das Relações

Públicas - 2000. Disponível em: <http://www.portalrp.com.br/bibliotecavirtual/responsabilidadesocial/0098.htm> Acesso em: 14 de maio 2011

IBASE. Modelo Ibase Balanço Social - 2011. Disponível em: <http://www.balancosocial.org.br/media/BS_Empresas2009.pdf> Acesso em: 13 de maio de 2011. 
MARIN, Waldir Amarante. Vantagens Obtidas ao Adotar Responsabilidade Social Empresarial - 2008.

Disponível em: <http://www.administradores.com.br/informe-se/producaoacademica/vantagens-obtidas-ao-se-adotar-a-responsabilidade-social-empresarial/995/> Acesso em: 20 de fevereiro de 2011.

MENDONÇA, Fernandes. Responsabilidade Social - 2004. Disponível em: http://www.fae.edu/publicacoes/pdf/revista_fae_business/n9/01_rs.pdf > Acesso em: 14 de maio de 2011.

NETO, Francisco Paulo Melo; FROES, César. Responsabilidade social e cidadania empresarial: a administração do terceiro setor - Rio de Janeiro: 1999.

REIS, Carlos Nelson dos; MEDEIROS, Luiz Edgar. Responsabilidade social das e balanço social, 1 ed. - Editora Atlas, S.A - 2009.

RESPONSABILIDADE Social, Revista Eletrônica. Balanço Social - 2011. Disponível em: <http://www.responsabilidadesocial.com/institucional/institucional_view.php?id=4> Acessado em: 29 de junho 2011.

RIBEIRO, Maisa de Souza. Contabilidade ambiental - São Paulo: Saraiva, 2006.

SILVA, César Augusto Tiburcio, FREIRE, Fátima de Souza (organizadores), Balanço Social - Teoria e Pratica - São Paulo: Atlas, 2001.

SILVA, Ernesto Antonio. Defensivos agrícolas - 2011. Disponível em:

<http://www.abrapa.com.br/jornais/979251865891093.pdf> Acesso em: 4 de maio de 2011.

TINOCO, João Eduardo Prudêncio. Balanço Social - São Paulo - Atlas, 2006. 